\title{
Clinicopathological features of colorectal polyps in 2002 and 2012
}

Yoon Jeong Nam, Kyeong Ok Kim, Chan Seo Park, Si Hyung Lee, and Byung Ik Jang

Division of Gastroenterology and Hepatology, Department of Internal Medicine, Yeungnam University College of Medicine, Daegu, Korea

Received: March 1, 2016 Revised : November 15, 2016 Accepted: June 7, 2017

\author{
Correspondence to \\ Kyeong Ok Kim, M.D. \\ Department of Internal Medicine, \\ Yeungnam University College of \\ Medicine, 170 Hyeonchung-ro, \\ Nam-gu, Daegu 42415, Korea \\ Tel: +82-53-620-3835 \\ Fax: +82-53-654-8386 \\ E-mail: kokim@yu.ac.kr
}

Background/Aims: There are few comparative studies on the historical changes in the clinicopathologic characteristics of colorectal polyps in Korea. This retrospective study compared the clinicopathologic characteristics of colorectal polyps treated at our institution in 2002 and 2012.

Methods: The medical records of 1,816 patients who underwent colonoscopy and were found to have colorectal polyps in $2002(\mathrm{n}=597)$ or $2012(\mathrm{n}=1,219)$ were reviewed retrospectively. Patient characteristics and polyp sizes, gross morphologies, locations, and pathologic results were analyzed and compared.

Results: Mean age was older in the 2002 group than in the 2012 group $(67.3 \pm 11.1$ years vs. $55.4 \pm 10.8$ years, $p<0.001)$. The 1,816 study subjects had a total of 3,723 colorectal polyps, with a mean of 2.05 polyps per patient. Mean polyp size was larger in the 2002 group than in the 2012 group $(0.6 \pm 0.4 \mathrm{~cm}$ vs. $0.4 \pm 0.3 \mathrm{~cm}, p<$ 0.001 ). The most common histology was tubular adenoma and they were more common in the right colon in both study groups. Although the distribution of total adenoma was not significantly different between groups, the location of advanced adenoma differed significantly and was more common in the right colon in the 2012 group (30.4\% vs. $63.2 \%, p=0.01$ ).

Conclusions: No significant change in total polyps and adenoma distribution was found between 2002 and 2012. However, advanced adenoma was more common in the right colon in 2012, which cautiously suggests a locational shift from the left to right colon. These findings indicate that right colon polyps require more attention.

Keywords: Colonic polyps; Distribution; Adenoma

\section{INTRODUCTION}

Eighty percent of colorectal cancers (CRCs) arise from preexisting adenomas [1], and the localization and anatomical distribution of adenomatous polyps are viewed with increasing importance. In the era of screening colonoscopy, the colorectal polyp detection rate is increasing. Colonoscopy continues to be considered as the gold standard screening tool for colon cancer prevention because it enables the removal of precancerous adenomas [2].

An estimated $30 \%$ of the Western population has colon polyps, but a lower rate (10\% to $15 \%)$ is reported for Asians and Africans [3,4]. In a recent Korean study on colonoscopy results obtained after health examinations, it was found that more than half of examinees older than 50 and one-thirds of young examinees, including individuals in their 30 s and 4OS, had colon polyps [5]. Previous studies have shown that colon polyps are more common in men than in women and that prevalence in- 
creases with age $[6,7]$.

A locational shift of colorectal adenomas and carcinomas toward the right colon has been observed in the United States and Europe [8,9], and time trend analysis has shown a progressive shift toward right-sided colon cancer in the past 40 years [10].

An understanding of the chronological changes in colorectal polyps and cancer is very important because these are associated with the efficacy of colorectal screening strategies. However, few chronological comparative studies have been conducted on colorectal polyps. In the present study, we compared the clinicopathological features of colorectal polyps recorded in 2002 with those documented in 2012, with focus on anatomical distribution.

\section{METHODS}

This was a retrospective observational study comparing clinicopathological differences over a 10-year period. Initially, the medical records of 4,791 patients who underwent colonoscopy at Yeungnam University Hospital in $2002(\mathrm{n}=1,562)$ and $2012(\mathrm{n}=3,229)$ were reviewed retrospectively. Patients were excluded if they had (1) a history of CRC, (2) a history of colectomy, (3) regular colonoscopy for previously diagnosed colorectal polyps, (4) inflammatory bowel disease, (5) hereditary polyposis syndrome, or (6) diagnosis of advanced CRC. However, patients with a confirmed intramucosal carcinoma after endoscopic or surgical resection were all included.

Of these 4,791 patients, 784 were excluded; of the remaining 4,007, 1,816 were found to have polyps ( $\mathrm{n}=$ 3,723). These 1,816 patients constituted the study cohort and were allocated to a 2002 group $(n=597)$ or a 2012 $\operatorname{group}(\mathrm{n}=1,219)$ (Fig. 1 ).

All polyps found during colonoscopy were removed using a biopsy forceps or by snare polypectomy, endoscopic resection and endoscopic submucosal dissection or surgery and were referred for histological examination.

The 2002 and 2012 groups were compared with respect to patient characteristics and polyp sizes, gross morphologies, distributions, and histologies. Polyp locations were classified into eight categories-cecum, ascending colon, hepatic flexure, transverse colon, splenic flexure, descending colon, sigmoid colon, and rectum-and then further classified as right- or left-side colon origin. Right-sided polyps were defined as any polyps detected between the splenic flexure and cecum, and left-sided polyps as polyps located distal to the splenic flexure. Polyp sizes were classified as follows: diminutive $(<5$ $\mathrm{mm}$ in diameter), small ( $\geq 5 \mathrm{~mm}$ to $<10 \mathrm{~mm}$ ), and large $(\geq 10 \mathrm{~mm}$ ). Gross morphologies were described as pedunculated (Ip), subpedunculated (Isp), sessile (Is), or flat (IIa), according to the Paris classification [11].

Histology was classified as neoplastic polyp including tubular adenoma, tubulovillous adenoma, villous adenoma, serrated adenoma, adenocarcinoma, or non-neoplastic polyp including hyperplastic polyp and inflammation. Cases of not able to be defined as neoplastic or non- neoplastic were all classified into others. Advanced adenoma was defined as villous or tubulovillous adenoma, high-grade dysplasia, intramucosal carcinoma, or as an adenoma of diameter $\geq 10 \mathrm{~mm}$.

Statistical analysis was carried out using SPSS version 15.0 (SPSS Inc., Chicago, IL, USA). Results are expressed as means and standard deviations for continuous variables or as percentages for categorical variables. Differences in clinical characteristics for different segments were analyzed using the chi-square test for categorical variables and by analysis of variance for quantitative

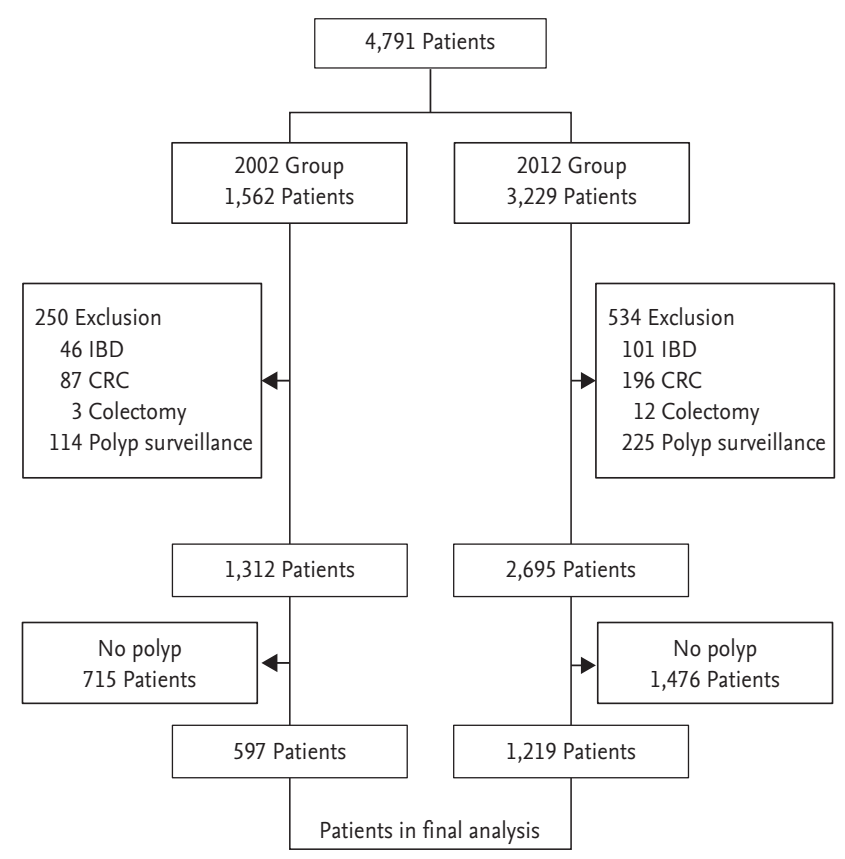

Figure 1. Study flow chart of enrolled patients. 
variables. Statistical significance was accepted for $p$ values $<0.05$.

This study was approved by the Institutional Review Board of Yeungnam University Hospital (YUH-130390-O38). Written informed consent by the patients was waived due to a retrospective nature of our study.

\section{RESULTS}

\section{Baseline characteristics and clinicopathological characteristics of polyps}

Among the 4,007 patients who met the inclusion criteria, 1,816 patients with polyps at colonoscopy were included in the analysis. The male to female ratio for all 1,816 study subjects was 1.5:1, and the male to female ratio in the 2012 group was significantly higher than in the 2002 group (1.8:1 vs. 2.3:1, $p=0.038$ ). On the other hand, mean age in the 2002 group was significantly higher than in the 2012 group $(67.3 \pm 11.1$ vs. $55.4 \pm 10.8, p<0.001)$.

The annual number of colonoscopic examinations performed doubled over the study period. When we consider the indications, 592 individuals (48.6\%) underwent colonoscopy during health examinations in 2012, but in 2002, most colonoscopies were performed because of symptoms or medical indications.
Polyp detection rate in 2002 was $45.5 \%$ and $45.2 \%$ in $2012(p=0.091)$. The mean number of polyps per patient was not different between groups $(2.2 \pm 1.7$ vs. $2.0 \pm 1.5, p$ $=0.056$ ). Adenoma was detected in $31.3 \%$ of the $4,007 \mathrm{pa}-$ tients; the adenoma detection rate did not show a significant difference between 2002 and 2012 (31.1\% vs. 31.5\%, $p=0.064$ ) (Table 1).

Polyps were more frequent in the left colon in both groups and there was no significant difference (Table 2). When we analyzed the distribution with only neoplastic polyps, they were both more common in right side colon (435/825 in 2002 vs. $767 / 1,379$ in 2012, $p=0.180$ ).

The flat type was the most common morphology in the 2002 group, but in the 2012, sessile type was most common. Mean polyp size was larger in the 2002 group ( $0.6 \pm 0.4 \mathrm{~cm}$ vs. $0.4 \pm 0.3 \mathrm{~cm}, p<0.001$ ) and tubular adenoma was the most common histology (61.6\% in 2002 and $54.5 \%$ in 2012) (Table 2).

\section{Clinical characteristics of advanced adenoma}

Of the 3,723 polyps excised, 113 were diagnosed as advanced adenoma, which was more common in the 2002 group $(56,4.4 \%$ vs. $57,2.3 \%)$. There was no significant difference in age of the patients with advanced adenoma $(67.8 \pm 10.5$ years vs. $64.1 \pm 12.5$ years, $p=0.226)$.

Rectum was most common location (25.7\%), followed

Table 1. Baseline characteristics of patients with colorectal polyp(s)

\begin{tabular}{|c|c|c|c|}
\hline Variable & 2002 Group & 2012 Group & $p$ value \\
\hline Sex, male:female & $1.8: 1$ & 2.3:1 & 0.038 \\
\hline Age, yr & $67 \cdot 3 \pm 11.1$ & $55.4 \pm 10.8$ & $<0.001$ \\
\hline Indication & & & 0.025 \\
\hline Screening/survaillance ${ }^{a}$ & $221(32.0)$ & $592(48.6)$ & \\
\hline Abdominal pain & $132(27.1)$ & $171(14.0)$ & \\
\hline Melena/hematochezia & $163(27 \cdot 3)$ & $204(16.7)$ & \\
\hline Others $^{\mathrm{b}}$ & $81(13.6)$ & $252(20.7)$ & \\
\hline Polyp detection rate ${ }^{c}$ & $597 / 1,312(45 \cdot 5)$ & $1,219 / 2,695(45 \cdot 2)$ & 0.091 \\
\hline Polyps per patients & $2.2 \pm 1.7$ & $2.0 \pm 1.5$ & 0.056 \\
\hline Adenoma detection rate ${ }^{d}$ & $408 / 1,312(31.1)$ & $849 / 2,695(31.5)$ & 0.064 \\
\hline Right:left:both & $187(31.3): 242(40.5): 168(28.2)$ & $391(32.1): 491(40.3): 337(27.6)$ & 0.945 \\
\hline
\end{tabular}

Values are presented as mean \pm standard deviation or number (\%).

${ }^{a}$ Only surveillance and follow-up after negative index colonoscopy were included.

${ }^{\mathrm{b}}$ Others included diarrhea and anemia.

${ }^{\mathrm{c}}$ Polyp detection rate was calculated from the number of patients with polyps divided by the total of included patients.

${ }^{\mathrm{d}}$ Adenoma detection rate was calculated from the number of patients with adenomatous polyps divided by the total of included patients 
Table 2. Clinicopathologic characteristics of 3,723 polyps

\begin{tabular}{|c|c|c|c|}
\hline Variable & 2002 Group $(n=1,277)$ & 2012 Group $(n=2,446)$ & $p$ value \\
\hline Location & & & 0.012 \\
\hline Cecum & $80(6.2)$ & $90(3.7)$ & \\
\hline Ascending colon & $259(20.3)$ & $544(22.2)$ & \\
\hline Hepatic flexure & $57(4 \cdot 5)$ & $98(4.0)$ & \\
\hline Transverse colon & $217(17.0)$ & $387(15.8)$ & \\
\hline Splenic flexure & $13(1.0)$ & $21(0.9)$ & \\
\hline Descending colon & $138(10.8)$ & $287(11.7)$ & \\
\hline Sigmoid colon & $291(22.8)$ & $611(25.0)$ & \\
\hline Rectum & $222(17.4)$ & $408(16.7)$ & \\
\hline Right:left & $626(49.0): 651$ (51.0) & $1,140(46.6): 1,306(53.4)$ & 0.767 \\
\hline Shape & & & $<0.001$ \\
\hline Pedunculated & $64(5.0)$ & $28(1.1)$ & \\
\hline Subpedunculated & $87(6.8)$ & $395(16.1)$ & \\
\hline Sessile & $55^{2}(43.2)$ & $1,433(58.6)$ & \\
\hline Flat & $574(45 \cdot 0)$ & $590(24.2)$ & \\
\hline Size, $\mathrm{mm}^{\mathrm{a}}$ & $0.6 \pm 0.4$ & $0.4 \pm 0.3$ & $<0.001$ \\
\hline Diminutive & $613(48.0)$ & $1,790(73.2)$ & \\
\hline Small & $429(33.6)$ & $541(22.1)$ & \\
\hline Large & $235(18.4)$ & $115(4.7)$ & \\
\hline Histology & & & $<0.001$ \\
\hline \multicolumn{4}{|l|}{ Neoplastic polyp } \\
\hline Tubular adenoma & $786(61.6)$ & $1,334(54.5)$ & \\
\hline Tubulovillous & $21(1.6)$ & $21(0.9)$ & \\
\hline Villous adenoma & $4(0.3)$ & $4(0.2)$ & \\
\hline Serrated adenoma & $3(0.2)$ & $13(0.5)$ & \\
\hline Adenocarcinoma & $11(0.9)$ & $7(0.3)$ & \\
\hline Non-neoplastic polyp & $435(34.1)$ & $1,063(43 \cdot 4)$ & \\
\hline Others $^{\mathrm{b}}$ & $17(1.3)$ & $4(0.2)$ & \\
\hline
\end{tabular}

Values are presented as number (\%) or mean \pm standard deviation.

${ }^{\mathrm{a}}$ Diminutive, $<5 \mathrm{~mm}$; small, $\geq 5$ to $<10 \mathrm{~mm}$; large, $\geq 10 \mathrm{~mm}$.

${ }^{\mathrm{b}}$ Adenomatous change, 15; atypical gland, 2; eosinophilic infiltration, 1 ; fat necrosis, 2; xanthoma, 1.

Table 3. Histologic and morphologic characteristics of advanced adenomas in the two groups

\begin{tabular}{|c|c|c|c|}
\hline Variable & 2002 Group $(\mathrm{n}=1,277)$ & 2012 Group $(n=2,446)$ & $p$ value \\
\hline Age, yr & $67.8 \pm 10.5$ & $64.1 \pm 12.5$ & 0.226 \\
\hline Location, right:left & $17(30.4): 39(69.6)$ & $36(63.2): 21(36.8)$ & 0.010 \\
\hline \multicolumn{4}{|l|}{ Shape } \\
\hline Pedunculated & $17(30.4)$ & $5(8.8)$ & \\
\hline Subpedunculated & $10(17.8)$ & $13(22.8)$ & \\
\hline Sessile & $17(30.4)$ & $18(31.6)$ & \\
\hline Flat & $12(21.4)$ & $21(36.8)$ & \\
\hline Size, cm & $1.5 \pm 0.8$ & $2.1 \pm 1.2$ & 0.145 \\
\hline
\end{tabular}


Table 3. Continued

\begin{tabular}{|c|c|c|c|}
\hline Variable & 2002 Group $(n=1,277)$ & 2012 Group $(n=2,446)$ & $p$ value \\
\hline Histology & & & 0.104 \\
\hline Tubular adenoma & $13(23.2)$ & $19(33 \cdot 3)$ & \\
\hline Villous adenoma & $4(7.1)$ & $4(7.0)$ & \\
\hline Tubulovillous adenoma & $12(21.4)$ & $14(24.6)$ & \\
\hline High grade dysplasia & $16(28.6)$ & $13(22.8)$ & \\
\hline Adenocarcinoma & $11(19.6)$ & $7(12.3)$ & \\
\hline
\end{tabular}

Values are presented as mean \pm standard deviation or number $(\%)$

Table 4. Locations and sizes of carcinoma in situ including high-grade dysplasia and intramucosal adenocarcinoma in the two groups

\begin{tabular}{lccc}
\hline Variable & 2002 Group $(\mathrm{n}=27)$ & 2012 Group $(\mathrm{n}=20)$ & $p$ value \\
\hline Age, $y \mathrm{r}$ & $66.5 \pm 9.8$ & $63.0 \pm 12.5$ & 0.404 \\
Location, right:left & $6(22.2): 21(77.8)$ & $13(65.0): 7(35.0)$ & 0.023 \\
Size, $\mathrm{cm}$ & $1.9 \pm 0.8$ & $2.4 \pm 1.4$ & 0.278 \\
\hline
\end{tabular}

Values are presented as mean \pm standard deviation or number (\%).

by the sigmoid (20.4\%) and ascending colon (17.7\%). In the 2002 group, $30.4 \%$ of advanced adenomas were located in the right colon, whereas in the 2012 group, 63.2\% were located in the right colon $(p=0.012)$. Mean size in the 2012 groups was larger than in 2002 group (1.5 $\pm 0.8 \mathrm{~cm}$ and $2.1 \pm 1.2 \mathrm{~cm}$, respectively) (Table 3).

Histologically, high-grade dysplasia or intramucosal carcinoma was diagnosed in 47 polyps ( 27 in 2002 and 20 in 2012). Intramucosal cancer and of high-grade dysplasia in the 2012 group were detected more frequently in the right colon (22.2\% vs. $65.0 \%, p=0.023$ ) (Table 4 ).

\section{DISCUSSION}

In Korea, the incidence of CRC has increased and the importance of prevention and screening of CRC has been emphasized [12]. Colnoscopy has been considered one of the most effective screening modalities because detection and remove of the colorectal polyp using colonoscopy can reduce the incidence of CRC by up to $90 \%$ $[1,13]$.

Youn et al. [14] reported that the detection rate of polyps had increased from 5.1\% in the 1970 s to $9.5 \%$ in the 1990s. In a recent Western study by Raju et al. [15], the rate of adenoma detection was $60 \%$ and the rate of precancerous lesion detection was as high as $66 \%$. In the present study, there was no significant change in the polyp detection rate over this 10-year period.

We also found that mean polyp size was significantly larger in 2002 than in 2012. This result presumably was associated with the increased performances of screening colonoscopy and equipment such as a cap in 2012. On the other hand, the sizes of intramucosal cancer and high-grade dysplasia among cases of advanced adenoma were about $5 \mathrm{~mm}$ larger in 2012. These differences in sizes reflect the recent increase in the endoscopic treatment of larger, advanced polyps, especially with endoscopic mucosal resection or submucosal dissection.

In our study, the prevalence of advanced adenoma was higher in 2002 than in 2012. However, it might be associated with the differences in indications and patients' age. Actually in 2002, patients underwent colonoscopy when they had symptoms; in 2012, screening or surveillance after negative index colonoscopy was most common. Older age predominated in 2002, also affecting the prevalence of advanced adenoma. Thus, we could not conclude that advanced adenomas decreased in 2012 compared with in 2002.

The incidence of right-sided colon cancer has been increasing in Korea and its clinical importance has been emphasized [16]. A recent study showed that the developmental pathways of left- and right-sided colon cancer and their responses to chemotherapy differs $[17,18]$. In 
addition, it has been suggested that the distribution of colon polyps started to shift from the left to right colon 10 years ago $[13,19,20]$. Our study also showed that neoplastic polyps were more common in right side colon in both groups; thus, it appears that the shift of adenoma to right colon began from 10 years ago in our study.

Interestingly, the distribution of advanced adenoma was different between groups. The possible causes are that we could not rule out the possibility of missed lesions at negative index colonoscopy although we excluded patients with a history of colon polyps at previous colonoscopy. Secondly, we cautiously suggested that our result could reflect the current polyp trend. Actually, several previous Western and Oriental studies reported a left to right shift of colorectal polyp and cancer [8-10].

The present study has several limitations. First, it is limited by its retrospective, single-center design. We could not identify risk factors such as smoking, family history, and body mass index completely. In that reasons, we could not represent the colorectal polyp trend in Korea. Second, the 2012 group contained more asymptomatic examinees and fewer older examinees with medical conditions than the 2002 group. The use of screening endoscopy continues to increase, mean patient age has fallen, and the small polyp detection rate is increasing. We tried to reduce selection bias by adopting strict criteria, and excluded patients who underwent follow-up colonoscopy after polypectomy. However, there were significant differences in age and gender, and these differences could have affected the results. However, we found no significant differences in the prevalence of polyps and total adenomas. Additionally, these results might suggest the possibility of an increase in other risk factors such as westernized diets and obesity in Korea. Nevertheless, the present study was conducted with a relatively large number of patients and shows a difference in distribution of advanced adenoma (left colon < right) between 2002 and 2012.

In conclusion, we found no significant difference in polyp prevalence and distribution between 2002 and 2012; however, advanced adenoma was more common in the right colon in 2012. Although a prospective, longterm study with a large number of patients is needed for confirmation, our results suggest that additional effort should be directed at detection and more active treatment of right-sided colon polyps.

\section{KEY MESSAGE}

1. Overally, there was no significant difference in polyp prevalence and distribution between 2002 and 2012.

2. Compared to 10 years ago, advanced adenoma was more common in right side colon and we need more attention when we exam right side colon.

\section{Conflict of interest}

No potential conflict of interest relevant to this article was reported.

\section{Acknowledgements}

This study was supported by 2015 Yeungnam University Research Grant.

\section{REFERENCES}

1. Nouraie M, Hosseinkhah F, Brim H, Zamanifekri B, Smoot DT, Ashktorab H. Clinicopathological features of colon polyps from African-Americans. Dig Dis Sci 2010;55:1442-1449.

2. Visovan II, Tantau M, Ciobanu L, Pascu O, Tantau A. Increasing prevalence of right-sided colonic adenomas in a high-volume endoscopy department in Romania: implications for colorectal cancer screening. J Gastrointestin Liver Dis 2014;23:147-151.

3. Coode PE, Chan KW, Chan YT. Polyps and diverticula of the large intestine: a necropsy survey in Hong Kong. Gut 1985;26:1045-1048.

4. Tony J, Harish K, Ramachandran TM, Sunilkumar K, Thomas V. Profile of colonic polyps in a southern Indian population. Indian J Gastroenterol 2007;26:127-129.

5. Jung KW, Park S, Kong HJ, et al. Cancer statistics in Korea: incidence, mortality, survival, and prevalence in 2009. Cancer Res Treat 2012;44:11-24.

6. Weston AP, Campbell DR. Diminutive colonic polyps: histopathology, spatial distribution, concomitant significant lesions, and treatment complications. Am J Gastroenterol 1995;90:24-28.

7. Villavicencio RT, Rex DK. Colonic adenomas: prevalence 
and incidence rates, growth rates, and miss rates at colonoscopy. Semin Gastrointest Dis 2000;11:185-193.

8. Greene FL. Distribution of colorectal neoplasms: a left to right shift of polyps and cancer. Am Surg 1983;49:62-65.

9. Chan AO, Hui WM, Chan CK, et al. Colonoscopy demand and practice in a regional hospital over 9 years in Hong Kong: resource implication for cancer screening. Digestion 2006;73:84-88.

10. Thorn M, Bergstrom R, Kressner U, Sparen P, Zack M, Ekbom A. Trends in colorectal cancer incidence in Sweden 1959-93 by gender, localization, time period, and birth cohort. Cancer Causes Control 1998;9:145-152.

11. van Doorn SC, Hazewinkel Y, East JE, et al. Polyp morphology: an interobserver evaluation for the Paris classification among international experts. Am J Gastroenterol 2015;110:180-187.

12. Cheng L, Eng C, Nieman LZ, Kapadia AS, Du XL. Trends in colorectal cancer incidence by anatomic site and disease stage in the United States from 1976 to 2005. Am J Clin Oncol 2011;34:573-580.

13. Siegel RL, Ward EM, Jemal A. Trends in colorectal cancer incidence rates in the United States by tumor location and stage, 1992-2008. Cancer Epidemiol Biomarkers Prev
2012;21:411-416.

14. Youn SJ, Kim NY, Kim YT, et al. Colorectal polyp in Korea. Korean J Gastroenterol 1991;23:450-458.

15. Raju GS, Vadyala V, Slack R, et al. Adenoma detection in patients undergoing a comprehensive colonoscopy screening. Cancer Med 2013;2:391-402.

16. Um WH, Kim HG, Jeon SR, et al. Clinical comparison for colon polyps between right and left colon in Koreans. Intest Res 2012;10:372-378.

17. Bufill JA. Colorectal cancer: evidence for distinct genetic categories based on proximal or distal tumor location. Ann Intern Med 1990;113:779-788.

18. Delattre O, Olschwang S, Law DJ, et al. Multiple genetic alterations in distal and proximal colorectal cancer. Lancet 1989;2:353-356.

19. Okamoto M, Kawabe T, Yamaji Y, et al. Flat-type early colorectal cancer preferentially develops in right-sided colon in older patients. Dis Colon Rectum 2005;48:101-107.

20. Lucendo AJ, Guagnozzi D, Angueira T, et al. The relationship between proximal and distal colonic adenomas: is screening sigmoidoscopy enough in the presence of a changing epidemiology? Eur J Gastroenterol Hepatol 2013;25:973-980. 